\section{$\underset{\substack{\text { hommes } \\ \text { \& migrations }}}{ }$}

\section{Hommes \& migrations}

Revue française de référence sur les dynamiques

migratoires

$1321 \mid 2018$

Les mots de l'exil dans l'Europe du XIXe siècle

\title{
Nathalie Azoulai, Les Spectateurs
}

Paris, POL, 2018, 306 pages, 17,90€

\section{Mustapha Harzoune}

\section{(2) OpenEdition \\ 1 Journals}

\section{Édition électronique}

URL : http://journals.openedition.org/hommesmigrations/4607

DOI : 10.4000/hommesmigrations.4607

ISSN : 2262-3353

\section{Éditeur}

Musée national de l'histoire de l'immigration

\section{Édition imprimée}

Date de publication : 1 avril 2018

Pagination : 183-184

ISBN : 978-2-919040-41-4

ISSN : 1142-852X

Référence électronique

Mustapha Harzoune, « Nathalie Azoulai, Les Spectateurs », Hommes \& migrations [En ligne], 1321 |

2018, mis en ligne le 01 avril 2018, consulté le 06 janvier 2021. URL : http://journals.openedition.org/ hommesmigrations/4607; DOI : https://doi.org/10.4000/hommesmigrations.4607 


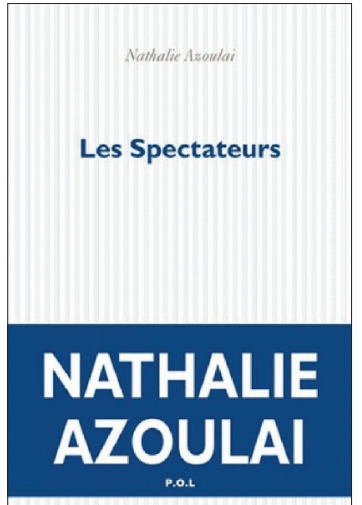

Nathalie Azoulai

Les Spectateurs

Paris, POL, 2018,

306 pages, $17,90 €$

Peu d'indications ici sur les personnages ou les situations, et les temporalités superposées ajoutent aux troubles du lecteur. Le pari est d'universaliser le propos, de désamarrer les attaches singulières pour constater que tous et chacun flottent sur les mêmes eaux d'intranquillité. Et c'est réussi.

Aux heures de gloire des Trente glorieuses, le prêt-à-porter et la télévision s'emparent des corps et des esprits. Chacun s'apprête à devenir le spectateur de sa vie. On pousse la porte d'un appartement d'une famille de Juifs exilés. Ils ont dû filer en 48 heures du pays qu'ils croyaient leur, "c'est inhumain, vous n'avez pas idée ». Cela fait douze ans. La mère était enceinte. Son garçon hérite d'un prénom difficile à porter. Douze ans plus tard, elle accouche d'une fille. Une luxation de la hanche l'oblige à se traîner. L'ado raconte. Pas de nom, pas de prénom. À l'exception de Maria et de son fils José, alias Pepito. La couturière réalise les robes - elle est « la confidente de mon corps » dit la mère. Pepito, lui, est le confident du fiston. Pour un temps.

La télévision fait la fierté du paternel. Madame préfère le cinéma. C'est une mordue des films hollywoodiens des années 1940, une fondue ("sa maladie " dit Maria) des robes que les Rita Hayworth et autres Hedy Lamarr portent à l'écran et dans les pages de Photoplay.

Le 27 novembre 1967, six mois après une lointaine guerre, le général de Gaulle tient une conférence de presse. Le père n'est pas allé au travail. Le fiston a séché les cours. Les mots claquent: "Un peuple d'élite, sûr de lui-même et dominateur". Ils marquent "la ligne du temps désormais fracturée, coupée en deux ». Devant l'écran, le père fulmine : "Voilà, pour nous, c'est fini la France!"; "Comment quitter un pays qu'on aime tant mais où on vous hait tant? (...) Quand est-ce qu'on sait qu'on doit partir? Vous savez, vous, puisque vous l'avez déjà fait", demande le fils. Spectateurs de l'histoire en marche sur un écran de télévision, ils savent qu'un discours peut se transformer en valises. On se croit spectateur d'une histoire 


\section{LIVRES}

lointaine, on la découvre en nous. Et cela hante le gamin qui a fait, secrètement, du libérateur de la France son héros et son idéal. Mais lui entend le velours prononcé par le Général, ce « s » placé là où il n'y en a pas: "Ce qu'ils avaient-z-été de tout temps." Et cela sonne comme "l'intrusion de ce cafard volant dans la maison. (...) II est peut-être devenu une bête lui aussi, une bête noire dans la nuit noire. Z'été, zété, bzzz... ». Le père emmène le fils manifester, en prenant soin de cacher la banderole. Les manifestants "depuis la guerre, on ne les avait plus vus ainsi regroupés »- «brandissent les deux drapeaux». 1967 ou l'irruption d'une citoyenneté aux appartenances plurielles, aux identités pluriterritorialisées. Avec son lot de suspicion: "De quelle patrie sont-ils vraiment les patriotes?" interroge de Gaulle dans les cauchemars de l'adolescent.

L'exil est l'autre fracture dans le temps et dans l'espace. II y a le pays d'avant et celui d'après, et les fissures qui restent. À son fils qui veut comprendre "ce moment où les familles se fracturent, se fendent ", la mère répond films ou actrices - son refuge - condamnant son rejeton "à vivre avec une origine fendue, un socle fissuré ». D'un arbre, il fait un soutien. Se tient en équilibre sur les mains, s'appuyant d'abord sur le tronc jusqu'à se sentir "enraciné », puis seul et longtemps, jusqu'à se purifier, se débarrasser « des bestioles et des idoles». Jusqu'à «marcher dans le ciel ».

À ces eaux communes d'intranquillité, il faut ajouter les émotions, que l'auteure excelle à faire passer : les jalousies silencieuses, les méchancetés vainement retenues, la haine ou la rage que l'on comprime, les hontes et les peurs. Et l'amour que l'on cache, mais dont l'évocation illumine encore le regard d'un corps fatigué.

M. H. 